\title{
The preservation of proto-Japanese tone class 2.5 in the Izumo region explained
}

\author{
Elisabeth M. DE BOER \\ Ruhr Universität Bochum, Bochum, Germany \\ elisabeth.boer@rub.de \\ Petros LOUKAREAS \\ Ruhr Universität Bochum, Bochum, Germany \\ petros.loukareas@rub.de
}

\begin{abstract}
In 1981, Okumura Mitsuo reported that the dialect of Izumo Taisha in western Japan had preserved remnants of the separate tone class 2.5 , which until then had only been found in dialects in central Japan. His discovery proved that this tone class had formed part of proto-Japanese, but the phonetic realization in Izumo and in central Japan was totally different. The article offers a reconstruction of the proto-system of the Izumo region, as well as an explanation of how class 2.5 came to be (partly) preserved in Izumo. It is argued that this was through a series of rightward shifts of the $/ \mathrm{H} /$ tone. These shifts radiated out from the northwestern part of the region. In the period, when the shifts were active, a contour tone on the second syllable of class 2.5 blocked rightward $/ \mathrm{H} /$ tone shift in this class. In this way, the contour tone, although later lost, left a trace in the modern dialects.
\end{abstract}

\section{Keywords}

influence of vowels on tone - rightward tone shift - blocking of tone shift - tone dots proto-Japanese - Japanese dialects - Ramsey's theory 


\section{Résumé}

En 1981, Okumura Mitsuo signala que le dialecte d' Izumo Taisha dans l'ouest du Japon préservait des vestiges de la classe tonale distincte 2.5 , qui jusqu' alors n' avait été trouvée que dans le centre du Japon. Sa découverte prouva que cette classe tonale faisait partie du proto-japonais, mais sa réalisation phonétique à Izumo et dans le centre du Japon était complètement différente. Cet article propose une reconstruction du protosystème de la région d' Izumo, ainsi qu' une explication de comment la classe 2.5 y a été (partiellement) conservée. Nous soutenons que ce fut par une série de déplacements tonals vers la droite du ton $/ \mathrm{H} /$. Ces déplacements ont rayonné depuis la partie nordouest de la région. Lors de la période où ces déplacements étaient actifs, un ton modulé sur la seconde syllabe dans la classe 2.5 bloqua le déplacement vers la droite dans cette classe. De cette manière, le ton modulé, bien que perdu par la suite, a laissé une trace dans les dialectes modernes.

\section{Mots-clés}

influence des voyelles sur les tons - déplacement tonal vers la droite - blocage du déplacement tonal - points tonals - proto-japonais - dialectes japonais - théorie de Ramsey

\section{Introduction}

One of the most contentious issues in the historical study of the Japanese tone system is the origin and status in the proto-system of tone class 2.5 , a small class of disyllabic nouns, which in most modern Japanese dialects is not distinguished from class $2.4{ }^{1}$ In the Kyōto type tone systems, where it is most commonly distinguished, it has phonological / $\mathrm{LH} /$ tone which, depending on the dialect, is phonetically realized as $[\mathrm{LF}]$ or $[\mathrm{LH}]$ in isolation. With attached monosyllabic particles (like $w a, g a, w o, n i$ ), it is realized as [LH-L]. Class 2.4 has $/ \mathrm{L} \varnothing /$ tone, which is realized as $[\mathrm{LH}]$, and with attached particles as $[\mathrm{LH}-\mathrm{H}]$ or [LL-H], depending on the dialect. ${ }^{2}$

1 "Syllable" in this article refers to short open syllables, as examples that contain long vowels, diphthongs, or other heavy syllables have been excluded.

2 Standard (Tōkyō type) Japanese is often analyzed as a pitch accent language, but in this article the dialects of Japanese are analyzed in terms of restricted tone. What are unaccented and accented syllables in the pitch accent analysis, are syllables with $/ \varnothing /$ tone and $/ \mathrm{H} /$ tone, 
In Middle Japanese, in some of the earlier tone dot manuscripts (such as in the Zushoryō-bon of Ruijumyōgi-shō of the late nth c.), a number of nouns of class 2.5 were marked on the second syllable with the rarely used tone dot for the "light even" tone. The light even tone dot marked a contour tone, reconstructed as a falling tone $/ F /$ in the standard reconstruction of the value of the tone dots by Kindaichi (1951). ${ }^{3}$ On the first syllable, class 2.5 was marked with the "even" tone dot, which Kindaichi reconstructed as a low tone /L/. Class 2.4 on the other hand, was marked on the first syllable with an even tone dot, and on the second syllable with a "rising" tone dot, reconstructed as a high tone $/ \mathrm{H} /$ by Kindaichi. Based on this interpretation of the tone dots, class 2.5 is therefore usually reconstructed as /LF/, and class 2.4 as /LH/ in Middle Japanese.

The light even tone dot fell out of use in the 12th century, but the contour tone did not disappear, at least not phonemically. In later manuscripts the contour tone can be detected through the influence it exerted on the tone of attached particles. In older manuscripts, particles like $w a, g a, w o$, and $n i$ had "rising" tone after both classes, but in later manuscripts they have "even" tone after class 2.5. Under the influence of the /F/ toneme on the final syllable, /LF$\mathrm{H} /$ was realized as [LH-L]. In other words, it is thought that by then, these tone classes were realized in a similar way to the modern Kyōto type tone systems, namely class 2.5 as [LH-L] and class 2.4 as [LH-H].

For a long time, it was thought that tone class 2.5 only existed in dialects with a Kyōto type tone system (cf. Tokugawa 1962). Class 2.5 was so strongly associated with the Kyōto type system that the existence of this class was even regarded as a diagnostic of this tonal type. Martin (1987:369) for instance, noticed that according to a table in Meikai Nihongo akusento jiten (Kindaichi 1958: 14), it seemed as though in Matsue, nouns of class 2.5 ending in $i$ or $u$, were the only ones with [HL-L] pitch, and that all other nouns ending in $i$ or $u$ had [LL-H] pitch. He commented: "The segregation of even a subset of the

respectively, in the tonal analysis. After a phonemic $/ \mathrm{H} /$ tone, there is a fall in pitch. In the Kyōto type dialects, in addition to $/ \mathrm{H} /$ tone and $/ \varnothing /$ tone, there is a $/ \mathrm{L} /$ toneme, which is restricted to the initial syllable. The Kyōto type dialects regularly have the $/ \mathrm{H} /$ tone one syllable earlier in the word than the Tōkyō type tone systems. When Tōkyō has an initial /H/ tone, the regular Kyōto reflex is an initial /L/ tone.

3 The membership of class 2.5 includes a large number of names of animals (Akinaga 1972: 5). To this can be added the names of many plants (De Boer 2010: 205). It is possible that some (diminutive?) suffix involved in naming was incorporated in the stem, generating the contour tone. We see some confirmation for this idea in the fact that in the modern dialect of Wakayama, the tone pattern of class 2.5 imposes a connotation of oddness or cuteness to nicknames and terms for animals and plants (Martin 1987: 169). 
nouns of Type 2.5 would raise a problem in classifying this version of 'Matsue' as a Tōkyō type dialect." As the table was revised in a later edition, Martin concluded that the 1958 edition had been mistaken.

In 1981, Okumura Mitsuo reported exactly the same distinction as indicated in the 1958 edition for the dialect of Izumo Taisha, only 40 kilometers away from Matsue. By now, the distinction has been found in Hikawa (Uwano 2016: 30 ) and Hirata (Hirako 2017b) as well, so it seems that the distinction is common to the northwestern part of the Izumo dialect area. Matsue turns out to be an intermediate dialect that has preserved remnants of this distinction.

The fact that class 2.5 turned up in a region so far removed from Kyōto is important, as it means that this tone class must go back to the proto-language. So far though, there has been no reconstruction of the process through which part of tone class 2.5 remained distinct in the Izumo area. Nor has there been a reconstruction of the tonal shape that this tone class may have had, as opposed to class 2.4 in the proto-system of the region.

What is clear from a comparison of the tone systems of Izumo with those of other Tōkyō type dialects and with each other, is that the area is rich in rightward tone shifts, and that these shifts are conditioned by vowel height. Different dialects in the Izumo region show different stages in a process of rightward shift; in some areas the shifts have progressed further than in others. In this paper we will argue that class 2.5 was able to leave an imprint on a number of modern dialects in the region, as a result of these shifts.

\section{$2 \quad$ Rightward tone shift in the Gairin tone systems}

The tone system of Izumo belongs to the so-called Gairin Tōkyō type tone systems. The Tōkyō type tone systems are divided into a number of sub-types based on the fact that they have different merger patterns of the tone classes. The Gairin type is found in (1) northern Kyūshū, (2) Shimane (the areas of Izumo, Matsue, and Yonago) and the adjacent western part of Tottori, (3) western Shizuoka and the adjacent eastern part of Aichi, (4) the Tōhoku region, and (5) Hokkaidō. The / $\mathrm{H} /$ tone is usually in the same location as in Tōkyō (which belongs to the so-called Chūrin sub-type of the Tōkyō type tone systems), but where Tōkyō has word-final /H/ tone in tone classes 2.2 and 3.2, the Gairin tone systems have lost these $/ \mathrm{H} /$ tones. Class 2.2 has therefore merged with class 2.1, and class 3.2 has merged with class 3.1, which contain only $\varnothing$ tones (the "unaccented" classes). In a typical Gairin type tone system, the disyllabic tone classes are as follows: The merged classes 2.1 and 2.2 are $[\mathrm{LH}-\mathrm{H}](|\varnothing \varnothing-\varnothing|$, no phono$\operatorname{logical} / \mathrm{H} /$ tone, or unaccented), class 2.3 is $[\mathrm{LH}-\mathrm{L}](/ \varnothing \mathrm{H}-\varnothing /, / \mathrm{H} /$ tone on the 
TABLE 1 Comparison of the disyllabic tone classes in the Gairin dialect of Oita and in the Tōkyō standard dialect

\begin{tabular}{lllllll}
$\begin{array}{l}\text { Tone } \\
\text { class }\end{array}$ & Example & Gloss & $\begin{array}{l}\text { Ōita } \\
\text { (Gairin A) }\end{array}$ & $\begin{array}{l}\text { Phonological } \\
\text { representation }\end{array}$ & $\begin{array}{l}\text { Tōkyō } \\
\text { (Chūrin) }\end{array}$ & $\begin{array}{l}\text { Phonological } \\
\text { representation }\end{array}$ \\
\hline 2.1 & kane & 'metal' & LH-H & $\varnothing \varnothing-\varnothing$ & LH-H & $\varnothing \varnothing-\varnothing$ \\
2.2 & isi & 'stone' & LH-H & $\varnothing \varnothing-\varnothing$ & LH-L & $\varnothing \mathrm{H}-\varnothing$ \\
2.3 & yama & 'mountain' & LH-L & $\varnothing \mathrm{H}-\varnothing$ & LH-L & $\varnothing \mathrm{H}-\varnothing$ \\
2.4 & ita & 'board' & HL-L & H $\varnothing-\varnothing$ & HL-L & H $\varnothing-\varnothing$ \\
2.5 & saru & 'monkey' & HL-L & H $\varnothing-\varnothing$ & HL-L & H $\varnothing-\varnothing$
\end{tabular}

second syllable), and the merged classes 2.4 and 2.5 are both [HL-L] (/H $\varnothing-\varnothing /$, /H/ tone on the initial syllable). See Ōita in Table 1.

Rightward shift of the /H/ tone conditioned by vowel height occurs in a number of the areas with Gairin type tone systems. The Gairin type tone systems can be largely divided into two sub-types, based on whether they have such tone shifts or not. We will refer to the type that has such shifts as type B, and to the type that does not (such as Ōita in Table 1), as type A. ${ }^{4}$ The choice of names reflects the fact that the system without the tone shift represents the more archaic variant (Gairin A), from which, in certain parts of Japan, the type with the tone shifts (Gairin B) developed.

The archaic nature of type $A$ is clear from the peripheral geographical distribution of this type in Shimane and Tottori. Figure 1 shows the area with Gairin type tone. Each circle shows the location of the $/ \mathrm{H} /$ tone on the first or second syllable in one of the fieldwork locations included in Hiroto \& Ōhara (1953). The squares show the reflexes in fieldwork conducted by the second author. The areas where the $/ \mathrm{H} /$ tone is on the first syllable belong to the Gairin A tonal type. The Gairin B shift of the $/ \mathrm{H} /$ tone is clearly an innovation limited to a central area.

4 This phenomenon is not restricted to the Gairin tone systems. The Chürin type tone system of the Bōsō Peninsula (De Boer 2010: 182) and some tone systems in the Seto Inland Sea, such as in the dialect of Takamatsu on Shikoku (De Boer 2010: 188) and in the Higai dialect on Ömi Island (Fujiwara 1988), also have a rightward shift of the /H/ tone conditioned by vowel height. The avoidance of $/ \mathrm{H} /$ tone on close vowels may be related to the fact that close vowels naturally tend to be shorter than low vowels, and that this tendency has been exaggerated in Japanese (Vance 1987: 49). 


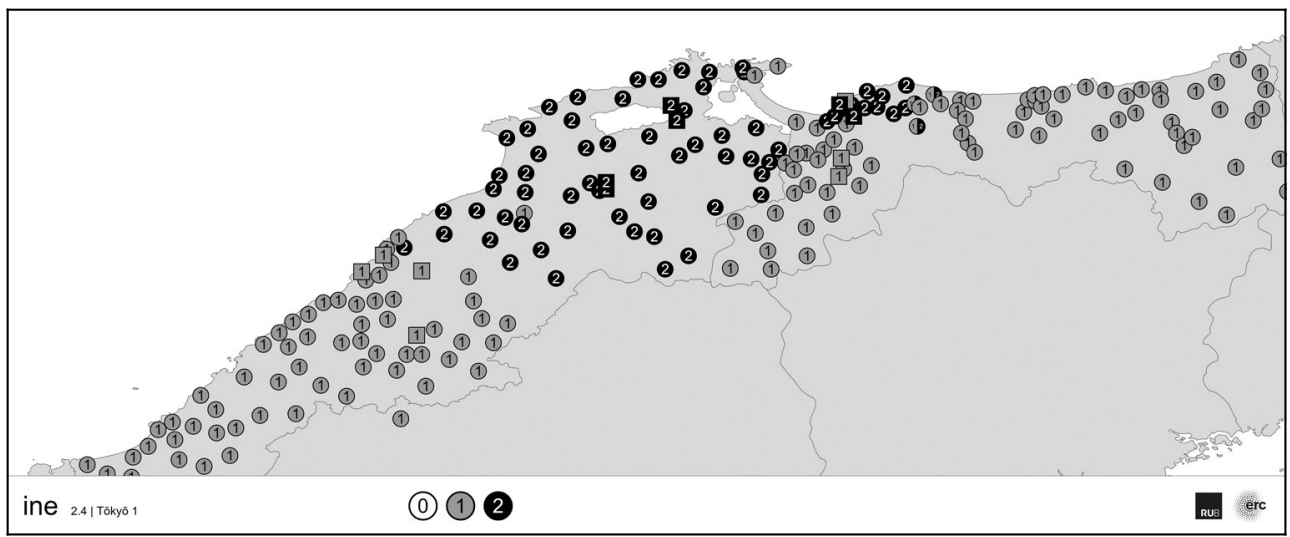

FIGURE 1 Location of the /H/ tone in ine 'rice plant' (tone class 2.4) in Shimane and western Tottori

The tone system of Izumo is especially rich in rightward shifts, but type B can also be found in a large area in northeast Honshū (such as in the dialects of Akita and Aomori) and in Hokkaidō. In several of these areas, two types of tone shifts are represented; an incipient type, and a more advanced type. We will call these types Gairin $\mathrm{B}_{1}$ and Gairin $\mathrm{B}_{2}$, respectively. The names again reflect which type is more archaic, and which type is the result of more innovations.

If we look at the disyllabic tone classes, in the Gairin B1 type, rightward shift of the $/ \mathrm{H} /$ tone from the first to the second syllable only occurs if two conditions are met. The first syllable must have a close vowel, and the second syllable an open vowel. We represent this structure as "I-A", where "I" stands for the close vowels $i$ and $u$, and "A" stands for the open vowels $a, e$, and $o$. This type is present in Mutsu city on the Shimokita peninsula, Hachinohe in Aomori, and Morioka in Iwate. ${ }^{5}$ In Izumo it is present in the northeastern part of the region. ${ }^{6}$ The word ine 'rice plant' in Figure 1 has an I-A structure, and areas that have the $/ \mathrm{H} /$ tone on the first syllable in Figure 1 therefore belong to the Gairin A tone system.

In the $\mathrm{B}_{2}$ type, the $/ \mathrm{H} /$ tone shifts to the right if the second syllable has an open vowel, irrespective of the quality of the vowel in the first syllable. This Gairin B2 type is also present in large parts of the Tōhoku region. The B1 dialects show that the process of $/ \mathrm{H} /$ tone shift originally started as a way for $/ \mathrm{H} /$ tone

5 In Mutsu city on the Shimokita peninsula: $2.4 / 5$ ido [LH] 'well' but aki [HL] 'autumn', ame [HL] 'rain'. Kindaichi (1983) reports the same for the dialects of Hachinohe and Morioka.

6 Hiroto (1961: 165), for instance, reported that in Nogi-gun to the east of Matsue, the first syllable has to contain a close vowel and the second syllable an open vowel for $/ \mathrm{H} /$ tone shift to occur: 2.4/5 hune [LH] 'ship', huna [LH] 'carp' but kasa [HL] 'umbrella', mado [HL] 'window'. 
TABLE 2 Influence of vowel quality on tone in the dialect of Matsue

\begin{tabular}{llllll}
\hline $\begin{array}{l}\text { Tone } \\
\text { class }\end{array}$ & Example & Gloss & $\begin{array}{l}\text { Final } \\
\text { vowel }\end{array}$ & Realization & $\begin{array}{l}\text { Phonological } \\
\text { representation }\end{array}$ \\
\hline $2.1 / 2$ & kane & 'metal' & A & LH-H & $\varnothing \varnothing-\varnothing$ \\
& isi & 'stone' & I & LL-H & $\varnothing \varnothing-\varnothing$ \\
2.3 & yama & 'mountain' & A & LH-L & $\varnothing \mathrm{H}-\varnothing$ \\
& asi & 'leg' & I & LL-H' & $\varnothing \mathrm{H}-\varnothing$ \\
$2.4 / 5$ & ita & 'board' & A & LH-L & $\varnothing \mathrm{H}-\varnothing$ \\
& matu & 'pine tree' & I & HL-L & H $\varnothing-\varnothing$ \\
\hline
\end{tabular}

to avoid the weaker close vowels $i$ or $u$. In these dialects, only words with I-A structure shift the $/ \mathrm{H} /$ tone. The shift later spread to words with an A-A structure. $^{7}$

The avoidance of $\mathrm{H}$ pitch on close vowels is not confined to the initial syllable and not limited to phonological $/ \mathrm{H} /$ tone. If the second syllable contains a close vowel, the automatic rise to $\mathrm{H}$ pitch after the first syllable (which is common in most Tōkyō type tone systems), is delayed in the dialects of this region. A word like mugibatake 'wheat field' for instance, is realized as [LLHHL], instead of [LH H HL]./H/ tone on a word-final syllable with a close vowel will also shift away to an attached case particle, if this particle contains an open vowel. After the particle there will be a drop in pitch. (This is represented by means of a mark after the particle (LL-H') in Table 2). This last shift appears to be the most recent one to occur. In 1981 for instance, Okumura still indicated that there was free variation between LH-L and LL-H' in the Taisha dialect in these cases. (See the next-to-last column in Table 5; the last column shows the present-day situation.) Table 2 shows the tone system of the dialect of Matsue, which is of the B2 type, in a somewhat regularized form. ${ }^{8}$

In the northwestern part of the Izumo region, there are dialects where a close vowel in the second syllable no longer blocks rightward tone shift in class 2.4.

7 What the dialects that avoid / $\mathrm{H} /$ tone on $i$ and $u$ both in Izumo and the Tōhoku region also have in common, is that $i$ and $u$ are centralized and merge after certain consonants. Opinions differ as to the origin of the similarities between these dialects (see De Boer et al. 2020; De Boer 2020).

8 As will be discussed later, Matsue preserves some remnants of class 2.5, as the percentages of the reflexes of this class differ from those of class 2.4. See Table 4. 
We will call this type, in which the shifts are most advanced, the Gairin B3 type. ${ }^{9}$ It is in these dialects that the distinction between class 2.4 and 2.5 has been preserved, as in nouns of class 2.5 this shift does not occur. That is, in words ending in close vowels, class 2.5 has $/ \mathrm{H} /$ tone on the first syllable, while class 2.4 has (a majority of) $/ \mathrm{H} /$ tone on the second syllable. It is this tonal type that was first described by Okumura (1981).

The paradoxical situation is therefore, that on the one hand, the $\mathrm{B}_{3}$ tone systems are the most innovative in the region as concerns the progression of the tone shifts, while on the other hand, they have most clearly preserved an archaic tone class distinction that is lost or less clearly preserved in the other dialects. We think this paradox is solved if we assume that, precisely because the $B_{3}$ dialects were ahead of the other dialects in shifting the tones, class 2.5 was still around in this area at the time of the shifts, and therefore able to influence the outcome of these shifts.

\section{Geographical distribution of the three Izumo tonal types, and the intermediate dialects in-between}

Hirako (2017a; 2017b) provides the most detailed data on the tone of classes 2.4 and 2.5 in a range of dialects from the Izumo region. ${ }^{10}$ The extensive vocabulary and large amount of dialect locations included in this excellent collection make it possible, for the first time, to reconstruct what the developments in the region must have been like.

Hirako (2017b) compares the distribution of the three tonal types to an earlier division into sub-dialects by Hiroto (1950), which was based on vocabulary, segmental phonology, and morphology. Hiroto divided the Izumo dialects into a northwestern dialect (with Izumo-city as center), a southern dialect (with Oku-Izumo-chō as center), and a northeastern dialect (with Yasugi-city as center). The B1 tonal type coincides with Hiroto's northeastern dialect, the B2 tonal type coincides with Hiroto's southern dialect, and the $\mathrm{B}_{3}$ tonal type coincides with Hiroto's northwestern dialect (Figure 2). ${ }^{11}$

9 As can be seen in Table 4, this rightward shift is not absolute, as there are still members of class 2.4 that have initial $/ \mathrm{H} /$ tone.

10 The article (2017a) presents the raw data and the presentation handout (2017b) includes Hirako's analysis of the data.

11 What are called $\mathrm{B}_{1}, \mathrm{~B}_{2}$ and $\mathrm{B}_{3}$ here, are called $\mathrm{B}_{2}, \mathrm{~B}_{1}$ and $\mathrm{A}$, respectively, by Hirako. The types have been renamed in this article to make them reflect the progression of the tone shifts. The reason why Hirako assigned a different letter to the A tonal type (here called 


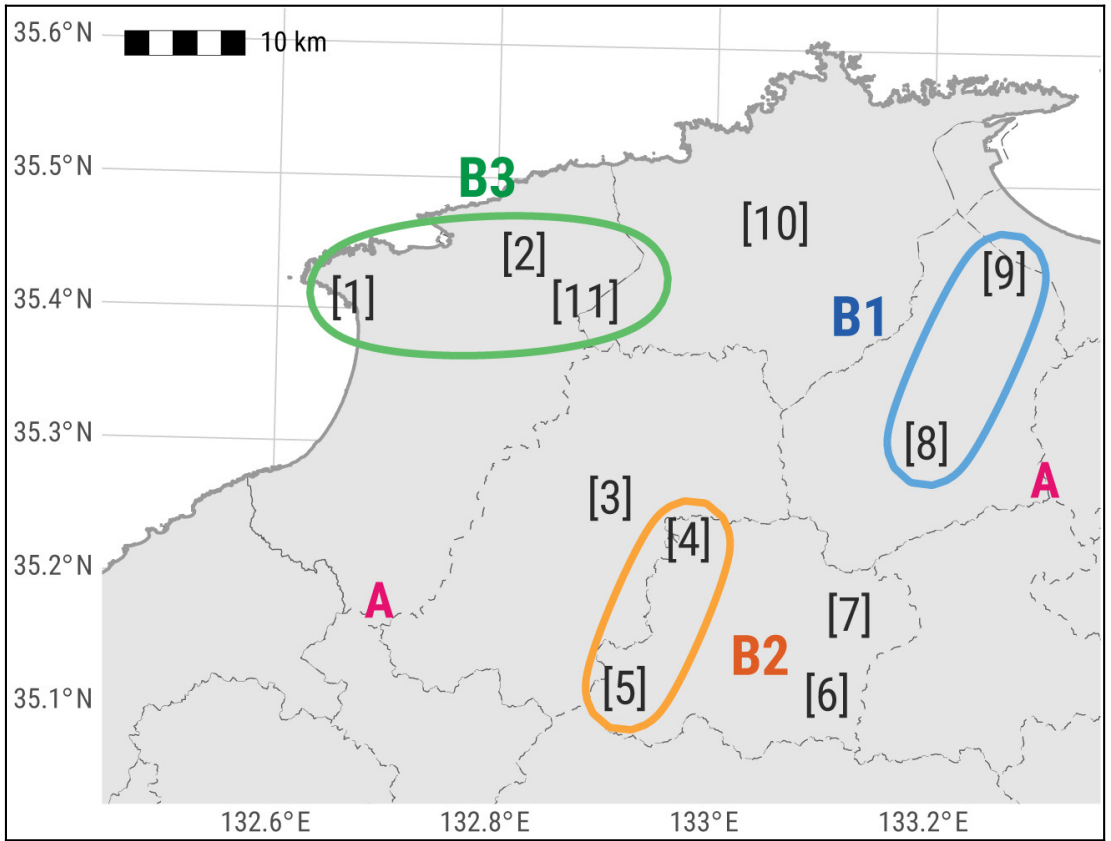

FIGURE 2 Map of the dialect locations included in Hirako (2017b), to which the names and outlines of the dialect areas have been added

The dialects that Hirako regards as the purest representatives of their tonal type are Tokami [9] for B1, Kami-Ai [5] for B2, and Taisha [1] for B3. Between the core dialects, there are zones where the reflexes represent intermediate patterns. The characteristics of the core dialects are not always as clear-cut as in the descriptions below. The reflexes will be discussed in more detail in section $7 \cdot \cdot^{12}$

$\left.B_{3}\right)$, is because he regards it as the only type that has preserved the distinction between classes 2.4 and 2.5. In our opinion, the B2 tone systems, even the "pure" ones (those that are hardly influenced by the shift of $/ \mathrm{H} /$ tone in words ending in close vowels in class 2.4) have in fact preserved remnants of class 2.5. In B2 systems like Kami-Ai and Sajiro for instance, there is a considerable difference in the percentage of words with A-A structure that have shifted the $/ \mathrm{H} /$ tone between class 2.4 (Kami-Ai 74\%, Sajiro 86\%) and class 2.5 (Kami-Ai $53 \%$ and $50 \%$ ). We therefore see no reason to set type $\mathrm{B}_{3}$ strongly apart. If anything, there is more reason to set type $\mathrm{B} 1$ apart, as this is the only type in which the reflexes of class 2.4 and 2.5 are truly equal, and therefore the only type that has really merged classes 2.4 and 2.5 .

12 The data for Hikawa and Matsue included in Hirako (2017b) are from Uwano (2016) and (1981a), respectively. 


\section{- B1 dialects}

Words of class 2.4 and 2.5 with I-A structure have merged with class 2.3 (rightward tone shift).

- [9] Tokami dialect

- [8] Unami dialect

\section{- B2 dialects}

Words of class 2.4 and 2.5 with I-A and A-A structure have merged with class 2.3 (rightward tone shift).

- [5] Kami-Ai dialect

- [4] Sajiro dialect

\section{- B3 dialects}

Words of class 2.4 have merged with class 2.3 (rightward tone shift). Words of class 2.5 with I-A and A-A structure have merged with class 2.3 (rightward tone shift), but words ending in I have preserved the $/ \mathrm{H} /$ tone on the initial syllable.

- [1] Taisha dialect

- [2] Hirata dialect

- [11] Hikawa dialect (Uwano)

- Intermediate dialects (Between B1 and B2)

- [7] Ōro dialect: Intermediate between $\mathrm{B}_{1}$ and $\mathrm{B} 2$, but closer to B1. (A third of class 2.4/5 with A-A structure has rightward shift as in the B2 dialects).

- [6] Yakawa: Intermediate between B1 and B2. (Half of class 2.4/5 with A-A structure has rightward shift as in the $\mathrm{B}_{2}$ dialects).

- Intermediate dialects (Between B2 and B3)

- [10] Matsue dialect: Intermediate between $\mathrm{B}_{2}$ and $\mathrm{B}_{3}$, but closer to $\mathrm{B}_{2}$ (Less than half of class 2.4 ending in I has rightward shift as in the $\mathrm{B}_{3}$ dialects.)

- [3] Kisuki dialect: Intermediate between $\mathrm{B}_{2}$ and $\mathrm{B}_{3}$, but closer to $\mathrm{B}_{3}$. (More than half of class 2.4 ending in I has rightward shift as in the B3 dialects.)

\section{Hirako's view of the historical developments}

According to Hirako's reconstruction of the historical developments (2017b: 4 ), the tone systems of the region first split into the $B_{3}$ type (his type A), which preserved the distinction between classes 2.4 and 2.5 , and the $\mathrm{B}_{1} / \mathrm{B}_{2}$ type, where the distinction was lost. In the proto-system of the $B_{3}$ type, class 2.5 had $/ \mathrm{H} /$ tone on the first syllable, and class $2.4 \mathrm{had} / \mathrm{H} /$ tone on the second sylla- 
ble. ${ }^{13}$ In the proto-system of the $\mathrm{B} 1 / \mathrm{B} 2$ type, the combined class $2.4 / 5 \mathrm{had} / \mathrm{H} /$ tone on the first syllable.

Hirako does not attempt to reconstruct a common proto-system for the $\mathrm{B}_{3}$ and $\mathrm{B} 1 / 2$ types. The issue of what such a system would have been like is not mentioned, and the question of how the differences between these closely related tone systems developed is left unresolved.

According to Hirako, first, in the $\mathrm{B}_{1} / \mathrm{B}_{2}$ dialects words of I-A structure shifted the $/ \mathrm{H} /$ tone to the second syllable. Later, the $\mathrm{B}_{1} / \mathrm{B}_{2}$ type split into $\mathrm{B}_{1}$ and $\mathrm{B}_{2}$, when the $\mathrm{B}_{2}$ dialects extended the rightward shift to words of A-A structure. This view is clearly correct, as in the transitional area between these two dialect types it is possible to see a gradual transition from the B1 type into the $\mathrm{B} 2$ type.

Hirako's view of the dialects in-between the $\mathrm{B}_{2}$ and $\mathrm{B}_{3}$ type (Matsue and Kisuki) is completely different: Although he acknowledges a genetic link between the $\mathrm{B}_{3}$ dialects and the other two dialect types present in the Izumo region, he rejects the possibility that these intermediate dialects show a gradual development from the $\mathrm{B}_{2}$ tonal type to the $\mathrm{B}_{3}$ tonal type, similar to the gradual transition that is seen between the $\mathrm{B}_{1}$ type and the $\mathrm{B}_{2}$ type.

According to Hirako, the dialects located in-between were originally of the B2 type (one of the types that had lost the distinction between classes 2.4 and 2.5 early on). These $\mathrm{B} 2$ dialects then extended the rightward tone shift to words of the merged class $2.4 / 5$ that ended in close vowels.

The problem with this account is that the dialects in-between $\mathrm{B}_{2}$ and $\mathrm{B}_{3}$ (Matsue and Kisuki) do not shift the $/ \mathrm{H} /$ tone equally in classes 2.4 and 2.5. They only extend the rightward shift in words ending in close vowels to words that belong to class 2.4. Class 2.5 does not join in this shift. This refutes Hirako's claim that the distinction between 2.4 and 2.5 was lost early on in the B2 dialects.

In short, Hirako posits an early split between dialects that preserved the distinction between 2.4 and 2.5 and dialects that did not, but this idea is contradicted by the data. Furthermore, he does not address the problem of what the single ancestral tone system of the region must have been like. This matter though, is essential in solving the question of what happened historically. What kind of tone system offers the best explanation for the development of all of the three core systems in the region, as well as all the intermediate forms? 
A reconstruction of $/ \mathrm{H} /$ tone on the first syllable of class 2.5 in the proto-system makes sense, as $/ \mathrm{H} /$ tone on the initial syllable is most prevalent in this class. In all dialects, words of A-I and I-I structure still have $/ \mathrm{H} /$ tone on the initial syllable, and in the B1 tone systems words with A-A structure can be added to this group. In the Gairin A tone systems of the region as well, the $/ H /$ tone is also on the first syllable, even in words of I-A structure.

Hirako's idea that 2.4 may have had [LH] tone in the proto-system is based on the $\mathrm{B}_{3}$ tone systems only, where this is now the predominant (but not exclusive) reflex in case of all types of vowel combinations. ${ }^{14}$ For the B1 and B2 system however, such a reconstruction of class 2.4 in the proto-system is unworkable. Even if we assume that the $/ \mathrm{H} /$ tone retracted from final syllables ending in close vowels in the B2 tone systems, it is unlikely that such retraction would have occurred for words with A-A structure in the B1 systems, or in words with I-A structure in the Gairin A systems that are also present in the region. ${ }^{15}$ If this retraction took place in class 2.4, why not also in class 2.3, which has [LH] tone as well, in all these dialects? Not only do leftward shifts go against the general trend in the Izumo region, one would also have to assume that in the $\mathrm{B}_{1}$ and $\mathrm{B}_{2}$ dialects, $/ \mathrm{H} /$ tones shifted to the left in class 2.4 , but to the right in class 2.5 .

The only way to make sense of the different patterns in the region, is to reconstruct an initial $/ \mathrm{H} /$ tone both for class 2.5 and for class 2.4 in the protosystem of the region. What needs to be solved then is why class 2.5 lags behind in the rightward tone shifts.

The rightward shifts must have started in the $\mathrm{B}_{3}$ area of Izumo Taisha in the northwest: It is there that the shifts have progressed furthest, and the geographical distribution too, shows that they radiated out from that area. In the Taisha area at that time, some tonal feature still distinguished class 2.5 from class 2.4. When the $/ \mathrm{H} /$ tone shifted from the first to the second syllable in class 2.4 , this tonal feature prevented a similar shift from taking place in class 2.5 .

The preservation of remnants of class 2.5 in the region depended on an early start of the process of rightward tone shift, when whatever characterized the tone of class 2.5 was still there at the time when these shifts were active. Seen in this way, what seemed contradictory at first (the most innovative tonal type,

14 Nevertheless, in Hirata $30 \%$, and in Taisha $20 \%$ of words of class 2.4 ending in I have /H/ tone on the first syllable. We would have to assume that there had been leftward shifts in class 2.4, but rightward shifts in class 2.5 if we adopt his reconstruction.

15 Unless the idea is that the Gairin A tone systems of the region are of a completely unrelated lineage. 
the one at the forefront of the tone shifts, preserving an archaic tone class distinction) now makes sense.

If both classes originally had the $/ \mathrm{H} /$ tone on the initial syllable, the distinction between the two classes must have lain elsewhere. This leaves the second syllable as the most obvious option, which fits in well with the fact that, in Middle Japanese as well, it was a tonal feature of the second syllable that distinguished class 2.5 from class 2.4 .

In our reconstruction, class 2.5 in proto-Izumo was distinguished from class 2.4 by the presence of a phonological rising tone on the second syllable / HR/, which was realized as [HL-H] tone with an enclitic particle. As we will argue in section 8 , it is exactly such a proto-system, where class 2.5 had [HL-H] tone and class 2.4 [HL-L] tone, that can explain the reflexes in the various modern dialects in the Izumo region, without having to posit rightward tone shifts in class 2.5, and leftward tone shifts in class 2.4.

\section{Stages in the development of the Tōkyō type tone systems: Kindaichi vs. Ramsey}

Is it possible to find confirmation for such a reconstruction of classes 2.4 and 2.5 in other dialects in Japan? As mentioned, the phonetic realization of these classes in the two areas where they have been preserved (Izumo and central Japan) tends to be very different. There are, however, some exceptions. In some dialects in the periphery of the central Japanese area, the realization of these classes resembles that of Izumo. In these dialects, located on Noto Island, class 2.4 and 2.5 both have initial $/ \mathrm{H} /$ tone, but have not merged. According to Kindaichi (1954: 72), in the dialect of Nozaki and some other villages on Noto Island, the tones are as follows: 2.1 [LH-H], 2.2 and 2.3 [LH-L], 2.4 [HL-L], 2.5 $[\mathrm{HL}-\mathrm{H}]^{16}$

As the same particles have $[\mathrm{L}]$ pitch after class 2.4 , but $[\mathrm{H}]$ pitch after class 2.5 in these dialects, the underlying tonal structure of class 2.5 can be analyzed as $/ \mathrm{HR} /$ as opposed to $/ \mathrm{H} \varnothing /$ for class 2.4: When a particle attaches, class $2.5 \mathrm{is}$ realized with $[\mathrm{HL}-\mathrm{H}]$ tone, as the phonemic rise on the second syllable is realized on the enclitic particle.

The underlying tonal structure in the Noto Island dialects therefore agrees with our reconstruction of the proto-Izumo tone system. The fact that a similar

16 In more recent descriptions of similar tone systems on the island (Nitta 2005; Hirako 2015) the initial high in class 2.5 is described as slightly lower than the second [ML-H], which may be a recent development. 
TABLE 3 Stages in the transition from a Kyōto type tone system to a Tōkyō type tone system (Kindaichi 1954)

\begin{tabular}{|c|c|c|c|c|c|c|c|}
\hline & $\begin{array}{l}\text { Stage } 1 \\
\text { Middle Japanese }\end{array}$ & Stage 2 & $\begin{array}{l}\text { Stage } 3 \\
\text { Kyōto }\end{array}$ & Stage 4 & Stage 5 & $\begin{array}{l}\text { Stage } 6 \\
\text { Nozaki }\end{array}$ & $\begin{array}{l}\text { Stage } 7 \\
\text { Tōkyōo }\end{array}$ \\
\hline 2.1 & $\mathrm{HH}-\mathrm{H}=$ & $\mathrm{HH}-\mathrm{H}=$ & $\mathrm{HH}-\mathrm{H}=$ & $\mathrm{HH}-\mathrm{H}>$ & LH-H = & LH-H = & LH-H \\
\hline 2.2 & HL-H = & HL-H > & HL-L $=$ & HL-L > & LH-L $=$ & LH-L $=$ & LH-L \\
\hline 2.3 & LL-H > & HL-H > & HL-L = & HL-L > & LH-L $=$ & LH-L $=$ & LH-L \\
\hline 2.4 & $\mathrm{LH}-\mathrm{H}=$ & LH-H = & LH-H > & LL-H > & LL-L > & HL-L = & HL-L \\
\hline 2.5 & LH-L $=$ & $\mathrm{LH}-\mathrm{L}=$ & LH-L $=$ & LH-L $=$ & LL-H > & HL-H > & HL-L \\
\hline
\end{tabular}

form $(/ \mathrm{H} /$ tone on the first syllable for both classes, and $/ \mathrm{R} /$ tone on the second syllable for class 2.5), once existed in two geographically separated areas suggests that this phonetic form is an archaic remnant.

According to Kindaichi's theory on the historical development of Japanese tone, the Tōkyō type tone systems developed out of the Kyōto type. Based on the Noto dialects, Kindaichi reconstructed a number of intermediate stages in the transformation of a Kyōto type tone system into a Tōkyō type tone system.

According to Kindaichi's theory, all Tōkyō type tone systems in Japan-at some point - went through the stages in Table 3 . The dialects of Izumo too, would have had [HL-L] tone for class 2.4 and [HL-H] tone for class 2.5 at some point in their history. ${ }^{17}$

Kindaichi is, however, not the only linguist who reconstructed a stage in the Tōkyō type tone systems where class 2.4 had [HL-L] tone and class 2.5 [HL$\mathrm{H}]$ tone. A similar reconstruction follows from the theory proposed by Ramsey (1979; 1980). According to Ramsey, the value of the tone dots in Middle Japanese was not reconstructed correctly by Japanese linguists in the 193os and should be reversed. Such a reversal results in a reconstruction of / HL/ tone for class 2.4 and / $\mathrm{HR} /$ tone for class 2.5 in Middle Japanese. ${ }^{18}$ When this view is adopted (as in De Boer 2010; in press), the proto-system of the Izumo area and the tone sys-

17 The Gairin Tōkyō type tone systems have a difference in the tone of class 2.2 compared to Table 3, as in the Gairin systems class 2.2 merged with class 2.1, and not with class 2.3. In the Izumo region, the tones at stage 6 in the Table would therefore have been 2.1/2 [LH-H], 2.3 [LH-L], 2.4 [HL-L], 2.5 [HL-H].

18 According to this theory, the Middle Japanese tone system resembled that of Tōkyō rather than Kyōto. The Kyōto type tone systems developed later, through a leftward shift of the /H/ tone. 
tems of Noto Island do not have to be analyzed as a late stage that was preceded by a long and complicated series of parallel independent changes (cf. Table 3). A far more natural view is to recognize it as an archaic stage, still close to the system preserved in Middle Japanese. For the purpose of this article though, which focuses mainly on the processes that led to the preservation of the distinction between class 2.4 and 2.5 in part of the Izumo region, the question of how the proto-Izumo system came about, in Ramsey's way or in Kindaichi's way, can be temporarily put aside.

Table 4 shows a count of the reflexes for each structural type (I-A, A-A, I-I, AI) in the three core dialects: $\mathrm{B}_{1}$ (Tokami), $\mathrm{B}_{2}$ (Kami-Ai), $\mathrm{B}_{3}$ (Hirata and Taisha) and the intermediate dialects $\mathrm{B}_{1} / \mathrm{B}_{2}$ (Yakawa) and B2/B3 (Matsue and Kisuki). ${ }^{19}$ The order of the dialects in the table follows their geographical locations, with the western dialects to the left and the eastern dialects to the right.

Each of the structural types has been given a number. The lower the number, the earlier rightward tone shift is likely to have occurred. The combination of a close vowel in the first syllable, followed by an open vowel in the second syllable has the number 1 , as this is the structure most inducive for the $/ \mathrm{H} /$ tone to shift to the second syllable. An open vowel in the first syllable, followed by a close vowel in the second syllable on the other hand, has the number 4 as in this structural type $/ \mathrm{H} /$ tone is least likely to shift away from the first syllable. It can be seen, that moving down from structural type 1 to structural type 4 , the number of words that shift the $/ \mathrm{H} /$ tone tends to get progressively lower.

Number slots representing a majority reflex have been shaded. If reflexes are equal (or almost equal) both slots are shaded.

Looking only at class 2.4 , it would be possible to see the shifts as a still active process, radiating out from the Taisha area. As in each structural type, the percentage of words that have the $/ \mathrm{H} /$ tone on the second syllable gradually increases moving horizontally from Tokami in the east to Taisha in the west. More and more dialects shift the $/ \mathrm{H} /$ tone to the right, with some types

19 If a dialect had two alternative locations of the $/ \mathrm{H} /$ tone listed in the charts for class 2.4 and 2.5 included in Hirako (2017a; 2017b), both are included in the count. We have excluded words with long vowels or diphthongs ending in close vowels as in these cases $/ \mathrm{H} /$ tone on the first mora may be secondary. (These words are kyō 'today', kai 'oar', koi 'carp', ai 'indigo'.) It was not possible to include all dialects for lack of space in the table. The reflexes of Sajiro and Unami are virtually the same as those of Kami-Ai and Tokami, respectively. 
TABLE 4 Comparison of the location of the $/ H /$ tone in seven Izumo dialects
B3
B3
$\mathrm{B}_{3} / \mathrm{B}_{2} \quad \mathrm{~B}_{3} / \mathrm{B}_{2}$
B2
B2/B1
B1
Taisha Hirata Kisuki Matsue Kami-Ai Yakawa Tokami
[1]
[2]
[3]
[10]
[5]
[6]
[9]

position of $\begin{array}{lllllllllllllll}\sigma_{1} & \sigma_{2} & \sigma_{1} & \sigma_{2} & \sigma_{1} & \sigma_{2} & \sigma_{1} & \sigma_{2} & \sigma_{1} & \sigma_{2} & \sigma_{1} & \sigma_{2} & \sigma_{1} & \sigma_{2}\end{array}$ the $\mathrm{H}$ tone

\begin{tabular}{|c|c|c|c|c|c|c|c|c|c|c|c|c|c|c|}
\hline 2.4 & & & & & & & & & & & & & & \\
\hline $1 \mathrm{I}-\mathrm{A}$ & O & 10 & O & 10 & O & 10 & o & 10 & O & 10 & 1 & 9 & 2 & 8 \\
\hline $2 \mathrm{~A}-\mathrm{A}$ & 2 & 20 & 2 & 18 & 3 & 18 & 5 & 19 & 6 & 17 & 11 & 11 & 18 & 3 \\
\hline 3 I-I & 5 & 17 & 5 & 14 & 8 & 10 & 13 & 7 & 16 & 4 & 17 & 2 & 17 & 1 \\
\hline $4 \mathrm{~A}-\mathrm{I}$ & 1 & 9 & 4 & 7 & 4 & 6 & 9 & 3 & 10 & 1 & 9 & 1 & 10 & O \\
\hline
\end{tabular}

2.5

\begin{tabular}{|l|r|r|r|r|r|r|r|r|r|r|r|r|r|r|r|}
\hline 1 I-A & 2 & 5 & 2 & 5 & 1 & 6 & 2 & 5 & 2 & 5 & 1 & 6 & 1 & 6 \\
\hline 2 A-A & 4 & 13 & 4 & 12 & 5 & 11 & 7 & 10 & 8 & 9 & 8 & 8 & 15 & 1 \\
\hline I I-I & 2 & 1 & 3 & 0 & 3 & 0 & 3 & 0 & 4 & 0 & 3 & 0 & 3 & 0 \\
\hline 4 A-I & 9 & 1 & 12 & 0 & 9 & 2 & 11 & 0 & 11 & 0 & 11 & 0 & 11 & 0 \\
\hline
\end{tabular}

of words lagging behind, and others forging ahead, depending on the vowel combinations.

A comparison with class 2.5 shows that such an analysis in terms of an active process is impossible: In class 2.5 , a similar gradual increase is only there in words ending in open vowels. In words ending in close vowels there is no gradual increase in shifts moving from Tokami to Taisha, as rightward shift of $/ \mathrm{H} /$ tone is blocked almost completely in all dialects. The shift in class 2.4 in words ending in close vowels can therefore not be analyzed as an active process, as in that case it would affect nouns of class 2.5 as well.

It seems that there are two kinds of shifts that have to be distinguished: One involves words ending in open vowels (I-A and A-A); this type most likely started first, and may still be active even now. The other type of shift involves words ending in close vowels; this type most likely started later and was active for a shorter time and probably developed as a generalization of the earlier rightward tone shifts that were induced by vowel quality.

In words ending in close vowels, the gradual increase in $/ \mathrm{H} /$ tone on the second syllable in class 2.4 , moving horizontally from $\mathrm{B}_{2}$ to $\mathrm{B}_{3}$, can only be the result of a formerly active process that radiated out from the $\mathrm{B}_{3}$ area. In the 
period when this process was active, the $/ \mathrm{R} /$ tone on the second syllable of class 2.5 made this class immune to these shifts.

Looking at the patterns of the shaded slots, it can be seen that not only in the $\mathrm{B}_{3}$ tone systems, but also in the $\mathrm{B} 2$ tone systems, some vestiges of class 2.5 have been preserved: The transition between the $\mathrm{B}_{1}$ and $\mathrm{B} 2$ types is gradual. In the $\mathrm{B}_{2}$ type the percentage of words that shifted the $/ \mathrm{H} /$ tone to the second syllable in A-A words is still lower than in I-A words. In I-A words the shift is virtually complete, but in A-A words, class 2.4 has shifted about three quarter of nouns, and class 2.5 only half, resulting in two equally shaded slots for class 2.5 . This indicates that in the $\mathrm{B}_{2}$ tone systems, the $/ \mathrm{R} /$ tone on the second syllable of class 2.5 still existed when these shifts first reached the B2 area. Members of class 2.5 started to join the I-A and A-A shifts at a later time than class 2.4, only after the $/ \mathrm{R} /$ tone had been lost. In case of the I-A shift, the inducement to shift the $/ \mathrm{H} /$ tone was so strong that class 2.5 (almost) caught up with class 2.4, but in the case of the A-A shift, it never did. ${ }^{20}$

The same phenomenon is visible in the $\mathrm{B}_{3}$ tone systems, and in the tone systems in-between $\mathrm{B}_{2}$ and $\mathrm{B}_{3}$. The percentage of words of class 2.5 with I-A and A-A structure that shifted the $/ \mathrm{H} /$ tone is higher there than in the $\mathrm{B}_{2}$ tone systems, but still always lower than in words of class 2.4.

\section{The process through which class 2.5 was partly preserved}

If rightward tone shift starts to spread in a tone system where class 2.4 has $/ \mathrm{H} \varnothing /$ tone and class $2.5 / \mathrm{HR} /$ tone, there is nothing to stop the $/ \mathrm{H} /$ tone from shifting to the right in class 2.4, where the second syllable has $\varnothing$ tone. The $/ \mathrm{R} /$ toneme on the second syllable of class 2.5, on the other hand, would have to be erased for the $/ \mathrm{H} /$ tone to be able to shift. Although the $/ \mathrm{R} /$ tone was eventually lost in almost all dialects (excepting those on Noto Island), it would have definitely blocked and/or delayed rightward $/ \mathrm{H} /$ tone shift in this class.

In the $\mathrm{B}_{3}$ areas, where the tone shifts started, the $/ \mathrm{R} /$ tone was still present at the time, and so initially only class 2.4 joined in the tone shift. The first shift to radiate out from the $\mathrm{B}_{3}$ area would have been the shift in words of I-A structure. This shift is most natural, and it spread out farthest, reaching as far as the B1 area. By the time the shift had traveled that far east, class 2.5 had already

20 In Matsue, the pattern of the shaded slots in classes 2.4 and 2.5 agrees, but it is clear that there, too, class 2.5 lags behind in the rightward shift in words of A-A structure. An additional remnant of class 2.5 in this transitional $\mathrm{B}_{2} / \mathrm{B}_{3}$ dialect is that a third of words ending in I of class 2.4 have shifted the $/ \mathrm{H} /$ tone, but in class 2.5 none. 
been simplified there, and so in the $\mathrm{B} 1$ area both class 2.4 and class 2.5 shifted the $/ \mathrm{H} /$ tone. The $\mathrm{B}_{2}$ area was also reached, but earlier than the $\mathrm{B} 1$ area, because it is closer to the $\mathrm{B}_{3}$ dialects, and in the $\mathrm{B}_{2}$ dialects the $/ \mathrm{R} /$ tone in class $2.5 \mathrm{had}$ not yet disappeared. As a result, the B2 dialects of Kami-Ai and Sajiro shifted the $/ \mathrm{H} /$ tone in all words of I-A structure in class 2.4, but not in all words of class 2.5. This is because class 2.5 did join in the shift, but later than class 2.4 , only after the $/ \mathrm{R} /$ tone had been lost.

The second wave of rightward tone shift affected words of A-A structure. This shift never reached the $\mathrm{B} 1$ area, but it did spread out as far as the $\mathrm{B} 2$ area. Of class 2.4, 75\% shifted the $/ \mathrm{H} /$ tone in the B2 tone systems of Kami-Ai $(17$ out of 23 ) and $85 \%$ in Sajiro (18 out of 21), but of class 2.5, only half in both dialects. This difference, like the smaller difference between classes 2.4 and 2.5 in words of I-A structure mentioned above, can again be explained if class 2.5 was initially immune to the rightward shifts, and only later joined, after the $/ \mathrm{R} /$ contour tone in this class was lost. In Yakawa $\left(\mathrm{B}_{1} / \mathrm{B}_{2}\right)$, on the other hand, the percentages are equal (half/half) in both tone classes, indicating that in that area, class 2.5 had already merged with class 2.4 when the shift reached that far.

The last two shifts to spread out from the $\mathrm{B}_{3}$ area were in words ending in close vowels. In view of the tendency in a number of Japanese (especially Gairin) dialects to avoid /H/ tone on close vowels, these shifts are unusual. ${ }^{21}$ It is therefore not surprising that they were far more restricted geographically, and also active for a shorter period. These shifts spread primarily in the $B_{3}$ area, which is the only region where a strong majority of members of class 2.4 shifted the $/ \mathrm{H} /$ tone to the second syllable. In the intermediate dialects of Matsue and Kisuki, less than half (Matsue) or just over half (Kisuki) of words ending in close vowels of class 2.4 joined in this shift. In the B2 area only a few words of I-I structure joined, and almost none of A-I structure. As the /R/ tone in class 2.5 still existed in all of these areas at the time when these shifts were active, no vocabulary belonging to this class was affected.

21 Such complete rightward shifts have occurred in other Gairin type tone systems in Japan, such as in Arai near Lake Hamana and in northern Miyagi prefecture (Uwano 1981b), where class $2.4 / 5$ has merged with class 2.3 completely (We can perhaps call this tone system the Gairin B4 subtype). The division of the disyllabic nouns into distinct tone classes in this area is therefore $2.1 / 2$ vs. $2.3 / 4 / 5$, which is the same as in the word-tone system of Kagoshima. It is most likely no coincidence that rightward tone shift in a Gairin type tone system results in a merger pattern of the tone classes similar to that of Kagoshima. Rightward tone shift may have been a key factor in the development of the Japanese word-tone systems (De Boer 2020: 209-212). 


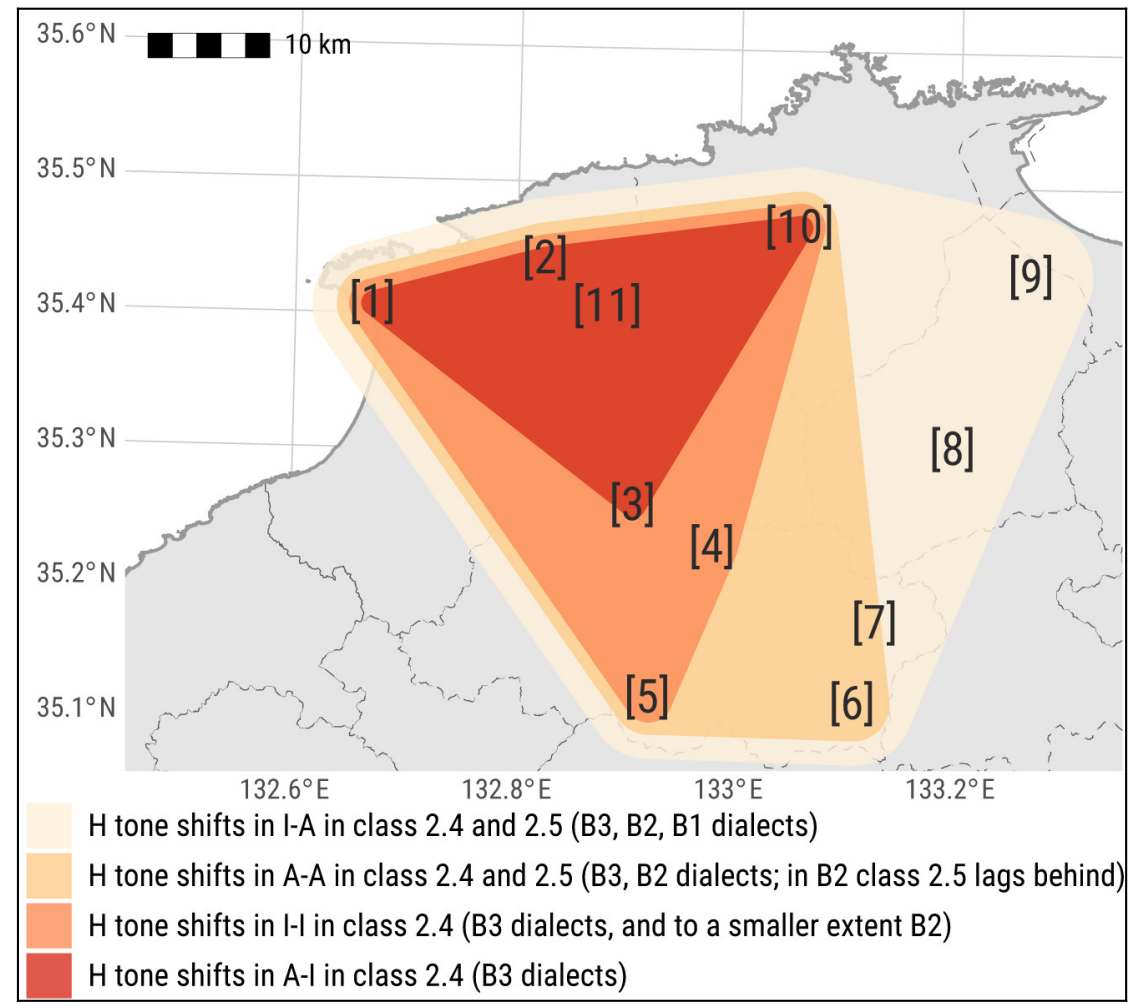

FIGURE 3 The geographical range of the different shifts

Tone class 2.5 simplified from [HL-H] to [HL-L] only after the rightward tone shift in words ending in close vowels had ceased to be active, and so class 2.5 is exempt from this shift. The shift in words of I-A and A-A structure on the other hand, remained active, and spread to class 2.5 after the tone of this class had been simplified. As we have seen however, class 2.5 still has lower percentages of these shifts than class 2.4.

If dialects where a certain shift is only present in marginal numbers are taken to be border areas, the data in Table 3 can be represented in a map as in Figure 3 .

The step by step process of rightward shift that resulted in the present-day B3 and B2 systems is illustrated in Tables 5 and 6. 
TABLE 5 Rightward tone shift in the $\mathrm{B}_{3}$ tone systems

\begin{tabular}{|c|c|c|c|c|c|c|}
\hline & $\begin{array}{l}\text { Stage } 1 \\
\text { (Proto-Izumo) }\end{array}$ & Stage $2-5$ & Stage 6 & Stage 7-8 & Stage 9 & $\begin{array}{l}\text { Stage 1o } \\
\text { (Taisha) }\end{array}$ \\
\hline \multicolumn{7}{|l|}{$2.1 / 2$} \\
\hline $1 \mathrm{I}-\mathrm{A}$ & LH-H & & & & & LH-H \\
\hline 2 A-A & LH-H & & & & & LH-H \\
\hline 3 I-I & LH-H & & & & LL-H & LL-H \\
\hline 4 A-I & LH-H & & & & LL-H & LL-H \\
\hline \multicolumn{7}{|l|}{2.3} \\
\hline $1 \mathrm{I}-\mathrm{A}$ & LH-L & & & & & LH-L \\
\hline 2 A-A & LH-L & & & & & LH-L \\
\hline 3 I-I & LH-L & & & & LH-L LL-H' & LL-H' \\
\hline 4 A-I & LH-L & & & & LH-L LL-H' & LL-H' \\
\hline \multicolumn{7}{|l|}{2.4} \\
\hline $1 \mathrm{I}-\mathrm{A}$ & HL-L & LH-L & & & & LH-L \\
\hline 2 A-A & HL-L & LH-L & & & & LH-L \\
\hline 3 I-I & HL-L & LH-L & & & LH-L LL-H' & LL-H' \\
\hline 4 A-I & HL-L & LH-L & & & LH-L LL-H' & LL-H \\
\hline \multicolumn{7}{|l|}{2.5} \\
\hline $1 \mathrm{I}-\mathrm{A}$ & HL-H & & HL-L & LH-L & & LH-L \\
\hline 2 A-A & HL-H & & HL-L & LH-L & & LH-L \\
\hline $3 \mathrm{I}-\mathrm{I}$ & HL-H & & HL-L & & & HL-L \\
\hline 4 A-I & HL-H & & HL-L & & & HL-L \\
\hline
\end{tabular}

$2.1 / 2$

$\begin{array}{llll}1 \text { I-A } & \text { LH-H } & & \text { LH-H } \\ 2 \text { A-A } & \text { LH-H } & & \text { LH-H } \\ 3 \text { I-I } & \text { LH-H } & \text { LL-H } & \text { LL-H } \\ 4 \text { A-I } & \text { LH-H } & \text { LL-H } & \text { LL-H } \\ 2 \cdot 3 & & & \\ 1 \text { I-A } & \text { LH-L } & & \text { LH-L } \\ 2 \text { A-A } & \text { LH-L } & & \text { LH-L }\end{array}$


TABLE 6 Rightward tone shift in the B2 tone systems (cont.)

\begin{tabular}{lllllll}
\hline & $\begin{array}{l}\text { Stage 1 } \\
\text { (Proto-Izumo) }\end{array}$ & Stage 2-5 & Stage 6 & Stage 7-8 & Stage 9 & $\begin{array}{l}\text { Stage 10 } \\
\text { (Kami-Ai) }\end{array}$ \\
\hline I-I & LH-L & & & LL-H' & LL-H' \\
4 A-I & LH-L & & & LL-H' & LL-H' \\
2.4 & & & & & \\
1 I-A & HL-L & LH-L & & LH-L \\
2 A-A & HL-L & LH-L & & LH-L \\
3 I-I & HL-L & (LH-L) & & HL-L \\
4 A-I & HL-L & & & HL-L \\
2.5 & & & & & LH-L \\
1 I-A & HL-H & & HL-L & LH-L & LH-L \\
2 A-A & HL-H & & HL-L & (LH-L) & HL-L \\
3 I-I & HL-H & & HL-L & & HL-L \\
4 A-I & HL-H & & HL-L & & \\
\hline
\end{tabular}

\section{9}

\section{Related issues}

Following Ramsey's reconstruction of the tone system of Middle Japanese, class $3.6 \mathrm{had} / \mathrm{HLL} /$ tone and class $3.7 \mathrm{had} / \mathrm{HLH} /$ tone. In tonal shape these classes therefore resembled classes 2.4 and 2.5. Were the developments in these classes in the type B tone systems of the Izumo region similar to those in classes 2.4 and 2.5 ? Did the $/ \mathrm{HLH} /$ tone of class 3.7 also delay rightward tone shift and result in a different location of the $\mathrm{H}$ tone?

A major difference is that unlike the distinction between classes 2.4 and 2.5, which was only preserved in the Tōkyō type tone systems of the Izumo and the Noto region, the distinction between classes 3.6 and 3.7 is preserved in many Tōkyō type tone systems. The reason why this distinction was far more widely preserved is most likely because the word-final $/ \mathrm{H} /$ tone in class 3.7 was based on a distinct syllable, whereas the word-final $/ \mathrm{R} /$ of class 2.5 had to be realized on an attached particle. The distinction between 3.6 and 3.7 was therefore far more stable.

In the Tōkyō type tone systems the distinction between classes 3.6 and 3.7 is preserved in the following way: In many Chūrin tone systems, the vocabulary of class 3.6 predominantly has $\varnothing$ tone, while class 3.7 has initial $/ \mathrm{H} /$ tone (mixed with some $\varnothing$ tone reflexes) such as in Tōkyō, Matsumoto, Numazu, Hiroshima 
(Hirayama 1960) and Yamaguchi (Kobayashi 1975). In fieldwork data from the Nairin dialect of Totsukawa, collected by our project, class 3.6 again has many unaccented reflexes, and 3.7 has a rather consistent initial $\mathrm{H}$ tone.

It is hard to explain why class 3.6 and (as well as part of class 3.7 in the Chürin dialects) developed $\varnothing$ tone. It is also unclear when this change occurred. The first author earlier proposed that rightward / $\mathrm{H} /$ tone shift may have occurred first in longer words, based on the tone system of the Shimokita peninsula (De Boer 2010: 185-186). In two syllable words this tone system belongs to the Gairin A type, but in three syllable words, the $/ \mathrm{H} /$ tone in classes 3.6 and 3.7 has shifted to the right, conditioned by vowel quality. It was suggested that $/ \mathrm{H} /$ tone shifting to the right in longer words may have been a wider tendency in Japanese, and that in those Tōkyō type tone systems that have a distinction between classes 3.6 and 3.7 the following could have happened:While $/ \mathrm{H} /$ tone shifted in class 3.6, the $/ \mathrm{HLH} /$ contour of class 3.7 prevented such a shift from occurring in class 3.7 . This process is very similar to what is reconstructed in the Izumo dialects in classes 2.4 and 2.5 .

As a result, class 3.6 developed $/ \mathrm{H} /$ tone on the second syllable in many dialects, while in class $3.7, / \mathrm{H} /$ tone remained on the first syllable. The medial $/ \mathrm{H} /$ tone in class 3.6 may then have disappeared, due to the tendency observed by Yoshida (1997) for medial /H/ tone in the Chūrin type tone system of Tōkyō to shift to $\varnothing$. Based on a comparison of the data in Hirayama (1957), $\mathrm{NHK}(1985)$, and her own research, she concludes that in trisyllabic nouns in Tōkyō, medial $/ \mathrm{H} /$ tone is disappearing. We are not aware of other attempts to explain the prevalence of $\varnothing$ tone in class 3.6 in part of the Japanese dialects.

Because some members of class 3.7 also have $\varnothing$ tone in many Chūrin dialects, class 3.7 is sometimes divided into two subclasses, $3.7 \mathrm{a}(\varnothing$ tone) and $3.7 \mathrm{~b}$ (initial H tone). See Hayata (1973) and Martin (1987: 632-633). Hirako (2017c) argues that the Gairin B tone systems of Shimane and the Gairin A tone systems of Aichi-Shizuoka also have $\varnothing$ tone in class 3.6, and that they share the split in class 3.7 that is found in the Chürin tone systems. He claims that in these Gairin tone systems (which he calls Inner Gairin) the same words of class 3.7 as in the Chürin tone systems have $\varnothing$ tone, and have merged with class 3.6. In his opinion therefore, these tone systems are more closely related to the Chürin tone systems than to the other Gairin tone systems (northern Kyūshū and Tōhoku/Hokkaidō), which he calls Outer Gairin, and where classes 3.6 and 3.7 have merged. ${ }^{22}$

22 In the Gairin A type of Ōita in northern Kyūshū (Hirayama 1960) classes 3.6 and 3.7 have a quite regular $/ \mathrm{H} /$ tone on the first syllable. In the Gairin B type of Tōhoku too, these classes have merged, but the location of the $/ \mathrm{H} /$ tone is more variable as it is influenced by vowel quality (cf. Aomori in Kobayashi 1975) 
There are several problems with this idea: First of all, it is not clear how old the $\varnothing$ tone reflexes in class 3.6 and part of 3.7 are in the Inner Gairin type tone system of Aichi/Hamamatsu. Nakajō (1983: 157) for instance, reports that in 1970, in this area, classes 3.6 and 3.7 had merged and that the dominant reflex for both classes was initial $/ \mathrm{H} /$ tone. Words of these classes that had $\varnothing$ tone in the Chūrin type tone system of Tōkyō (3.6 usagi 'rabbit', suzume 'sparrow', senaka 'spine', hibari 'lark', nezumi 'mouse' 3.7 itigo 'strawberry', usiro 'behind', kuzira 'whale') had initial /H/ tone in this area. According to him, an accent shift was under way, in which the younger generation started to adopt the Tōkyō $\varnothing$ tone reflexes.

Secondly, it is also unclear how old the $\varnothing$ tone reflexes of class 3.6 are in the Inner Gairin area of Shimane. Although many words of class 3.6 in the central Gairin B area in Shimane have $\varnothing$ tone, looking at the distribution of the reflexes in Hiroto \& Ōhara (1953), many of these words contain $/ \mathrm{H} /$ tone in the more conservative Gairin A areas surrounding the Gairin B type (E.g. unagi 'eel', kitune 'fox', tubame 'swallow', tonbo 'dragonfly', nagasa 'length', nezumi 'mouse', hidari 'left', hibari 'lark').

The fieldwork data collected in our project in Daisen-chō (Tottori) from the Gairin A area to the east of the central Gairin B area, indicate /H/ tone in suzume 'sparrow', mimizu 'earth worm', usagi 'rabbit', karasu 'crow', takasa 'length', hidari 'left', hibari 'lark', kitune 'fox', hadasi 'barefoot' and kamome 'seagull. (And the first 5 words have the $\mathrm{H}$ tone on the initial syllable.) See Figures 4 and 5 , which show the geographical distribution of the reflexes of 3.6 nezumi 'mouse' and 3.6 hidari 'left side' according to Hiroto and Ōhara and our fieldwork data. ${ }^{23}$

Is it possible that the $/ \mathrm{H} /$ tone loss in class 3.6 in the Gairin $\mathrm{B}$ tone systems in Shimane is linked in some way to the rightward tone shift? If so, it is unlikely that the lack of $/ \mathrm{H} /$ tone in this class goes back to proto-Japanese, and the tone of class 3.6 in the proto-Gairin tone system of Shimane can be best reconstructed with initial $\mathrm{H}$ tone.

Thirdly, in how far is the split between $3.7 \mathrm{a}$ and $3.7 \mathrm{~b}$ represented in the Inner Gairin areas? Even when comparing only the reflexes in the Chürin tone systems with each other, there is little consistency. Including the Inner Gairin tone systems in the comparison makes the inconsistency worse. Of the only 6 words that Hirako selects as having cross-dialect reflexes clear enough to assign them to the group with $\varnothing$ tone reflexes (itigo 'strawberry', kuzira 'whale', kusuri

23 Nezumi with A-I-I structure preserved the $\mathrm{H}$ tone on the initial syllable in the periphery, while hidari with I-A-I structure shifted the $\mathrm{H}$ tone to the second syllable in the $\mathrm{B}$ area. 


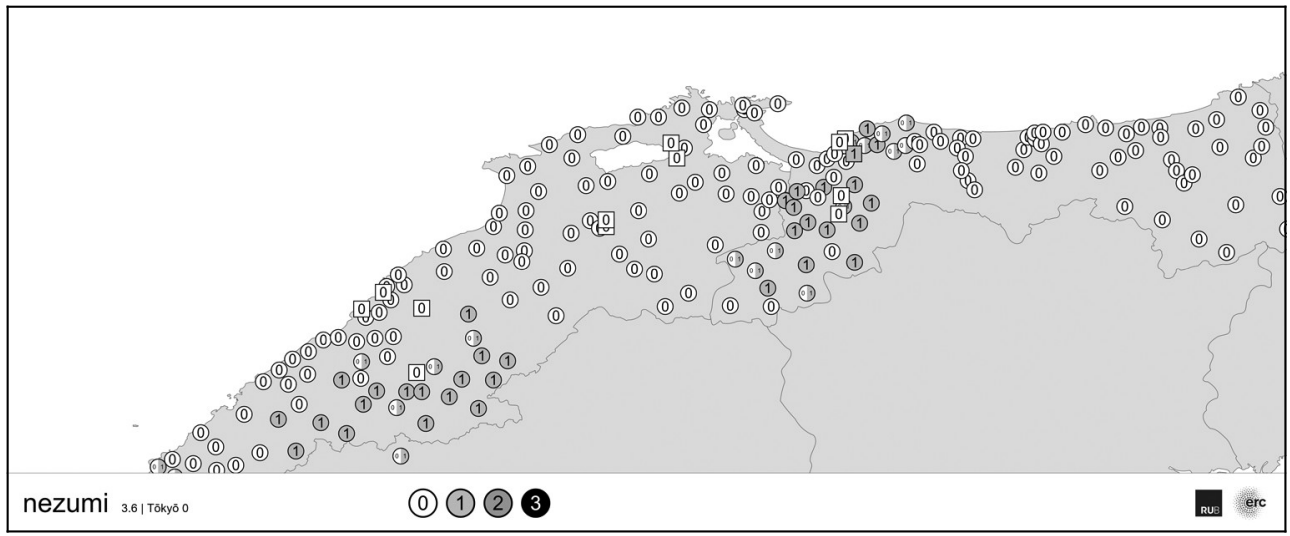

FIGURE 4 Location of the $/ \mathrm{H} /$ tone in nezumi 'mouse' (tone class 3.6) in Shimane and western Tottori

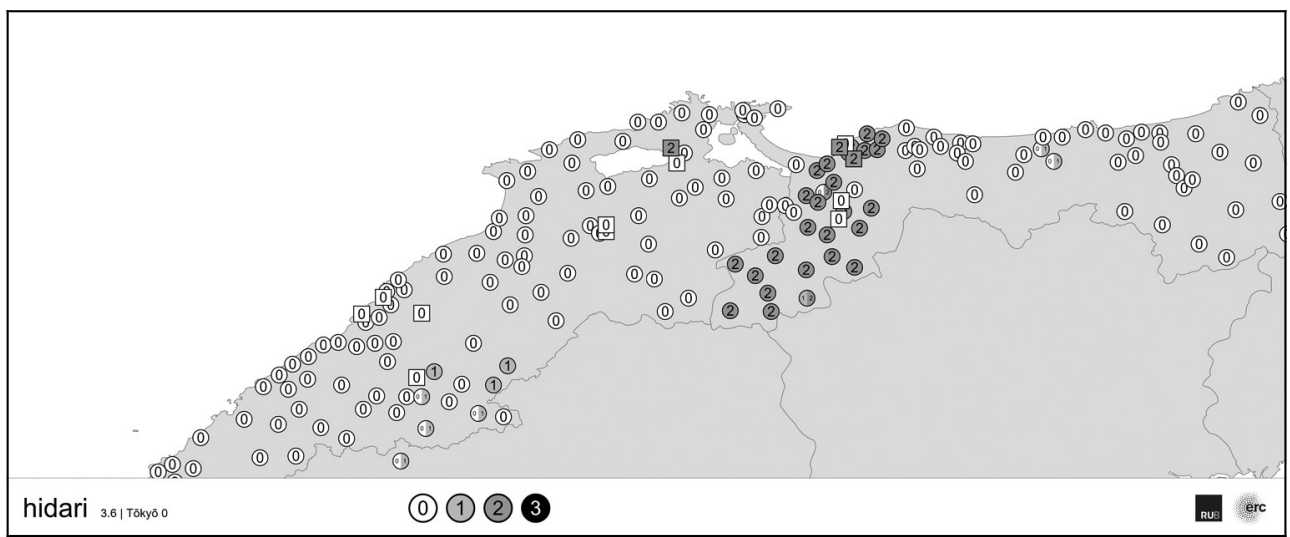

FIGURE 5 Location of the / $\mathrm{H} /$ tone in hidari 'left side' (tone class 3.6) in Shimane and western Tottori

'medicine', tarai 'washbowl', namari 'lead' and hatake 'field'), none have reflexes that are completely consistent. Even when only the three Shimane dialects in Hirako's table (Hirako 2017c: 273) are compared with each other, only kusuri 'medicine', namari 'lead', and hatake 'field' are consistent in having $\varnothing$ tone in all three dialects. In our fieldwork data from Daisen, of Hirako's 6 examples, 4 have a reflex with $/ \mathrm{H} /$ tone (itigo, kuzira, kusuri and tarai). In addition, in the peripheral Gairin A areas of Shimane and Tottori in Hiroto and Ōhara (1953), itigo, kuzira, namari, and hatake have a reflex with / $\mathrm{H} /$ tone. So even in case of kusuri, namari, and hatake the reflexes in Shimane are not consistent.

If we take the example of 3.7 kuzira 'whale', which belongs to Hirako's $\varnothing$ tone group, a look at the distribution of the reflexes may give an insight into what the oldest form of this word in Shimane and western Tottori may have been. 


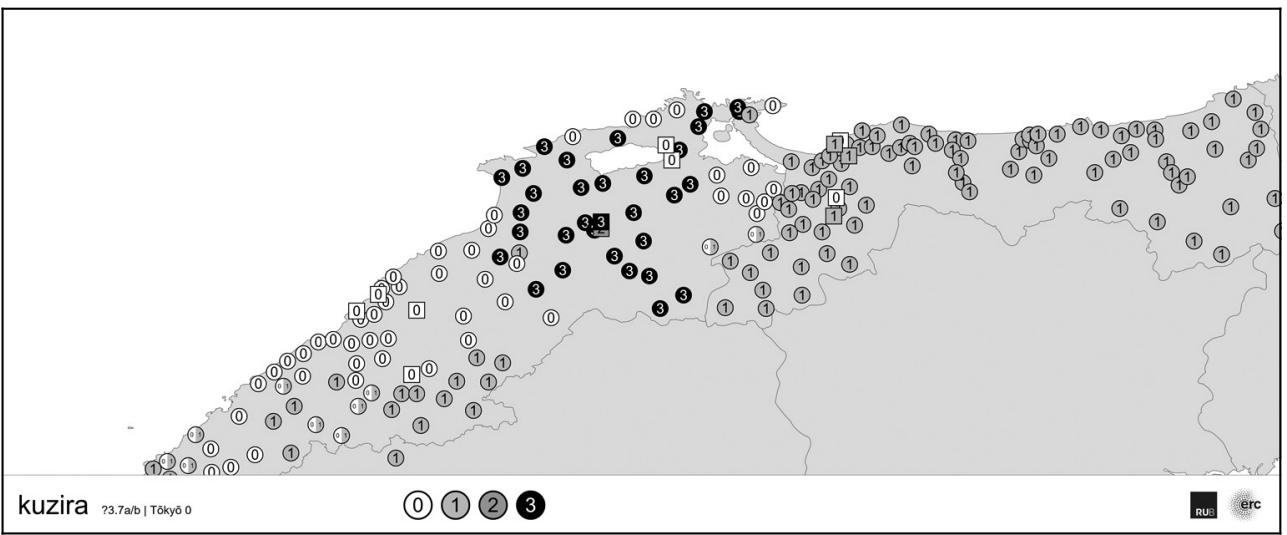

FIGURE 6 Location of the /H/ tone in kuzira 'whale' (tone class 3.7) in Shimane and western Tottori

The two dialects included in Hirako's table (Taisha and Tokami) both have $\varnothing$ tone. Comparing Figure 1 with Figure 6, which shows the reflexes according to Hiroto and Ōhara (1953) and our own fieldwork, it is clear that in 1953 the Tokami dialect was indeed in an area with $\varnothing$ tone, but at that time, the Taisha dialect still had $/ \mathrm{H} /$ tone on the third syllable. It can also be seen that in the conservative Gairin A areas in the periphery, $/ \mathrm{H} /$ tone on the initial syllable had been preserved. In the $\mathrm{B}$ areas, $/ \mathrm{H} /$ tone had shifted to the third syllable because of the I-I-A structure of kuzira, and in-between these areas there were areas with $\varnothing$ tone, which may have been the result of confusion. A reconstruction of $/ \mathrm{H} /$ tone on the first syllable of kuzira in the proto-system of the region therefore makes sense.

In short, in our opinion, the cause and background and age of the $\varnothing$ tone reflexes found in class $3.6 \mathrm{in}$ several areas of Japan is a mystery that needs to be cleared up before further conclusions can be drawn. We are not convinced that the division into $3.7 a$ and $3.7 b$ subtypes is shared by the Inner Gairin tone systems, as the group of words selected by Hirako for their similar reflexes is very small, and even this group contains many reflexes that do not fit the pattern.

Although the questions Hirako raises on the origin and implications of the $\varnothing$ tone reflexes in classes 3.6 and 3.7 are thought provoking, the article risks causing misunderstanding. Hirako (2017c: 274) includes a tree that has the Outer Gairin systems split off first from all other Japanese tone systems. ${ }^{24}$ Then the Chūrin and Inner Gairin systems split off together from the Nairin and the

24 The tree indicates that classes 3.6 and 3.7 are distinct in the Outer Gairin tone systems, but this must be a printing mistake, as the text of the article clearly indicates that Hirako sees these two classes as merged in the Outer Gairin areas. 
Kyōto type systems. It has to be noted though, that according to his explanatory notes, all developments happened independently, and so the Outer Gairin systems did not really split off together from the other systems. Nor did the Chürin and Inner Gairin systems split off together from the Nairin and Kyōto type systems. The tree included in the article is not a traditional genealogy, based on shared inherited innovations. It is merely a visualization of series of parallel independent developments that could have taken place at any time, in each area separately.

This means that Hirako's division into Inner and Outer Gairin, whether correct or not, has little bearing on the first author's claim (De Boer et al. 2020; De Boer 2020) that there is a close genetic link, born from a historical connection, between the dialects of Shimane/Tottori (Inner Gairin) and those of the Tōhoku region (Outer Gairin).

\section{Summary and conclusions}

A reconstruction of $/ \mathrm{H} /$ tone on the initial syllable in the proto-system of the Izumo region in tone classes 2.4 and 2.5 is the only way in which the differences in the reflexes of these tone classes in the present-day dialects can be explained, without having to resort to leftward shifts in some tone classes and rightward shifts in others. The reconstruction of / $\mathrm{HR} /$ tone in class 2.5 , as opposed to $/ \mathrm{H} \varnothing /$ tone in class 2.4, explains why rightward $/ \mathrm{H} /$ tone shift was initially blocked in class 2.5. The variation in the degree in which class 2.5 still lags behind in these shifts depends on the period in which the rightward shifts reached the different dialects. This, in turn, depends on the geographical distance of the dialects from the $\mathrm{B}_{3}$ area, the area from where the rightward shifts spread out.

The special tonal shape of class 2.5 blocked and delayed rightward shift in those dialects where the shifts were active at a relatively early time, when the $/ \mathrm{R} /$ tone was still present. The $/ \mathrm{R} /$ tone on the second syllable of class 2.5 was eventually lost, as it was in almost all Tōkyō type tone systems. However, it left an imprint in those dialects where the shifts occurred early on by causing a difference in the location of the $/ \mathrm{H} /$ tone between class 2.4 and 2.5. In areas where the shifts arrived late, such as in the eastern periphery of the Izumo region, the $/ \mathrm{R} /$ contour tone had already disappeared by that time, and there is no difference in the location of the $/ \mathrm{H} /$ tone between classes 2.4 and 2.5 .

The reconstruction of / $\mathrm{HR} /$ tone for class 2.5 in the proto-system agrees with Ramsey's reconstruction of the tones of Middle Japanese, and has independently been preserved in some dialects on Noto Island. The reconstruction of the proto-Izumo tone system and the process of rightward tone shift outlined 
above offers a unified explanation for the partial preservation of class 2.5, as well as for the development of the three different Gairin B type tone systems and the many intermediate forms found in the region.

\section{Acknowledgments}

This project has received funding from the European Research Council (ERC) under the European Union's Horizon 2020 research and innovation programme under grant agreement № 677317 .

\section{References}

Akinaga, Kazue. 1972. Kokin waka-shū shöten-bon no kenkyū, kenkyü-hen [A study of the tone dot manuscripts of Kokin waka-shü: Research volume]. Tokyo: Azekura Shobō.

De Boer, Elisabeth M. 2010. The historical development of Japanese tone: Part 1 From proto-Japanese to the modern dialects. Part 2 The introduction and adaptation of the Middle Chinese tones in Japan. Wiesbaden: Harrassowitz.

De Boer, Elisabeth M. 2017. Review of Handbook of the Ryukyuan languages: History, structure and use. Studies in Language 41(1). 781-79o.

De Boer, Elisabeth M. 2020. The classification of the Japonic languages. In Robbeets, Martine \& Savelyev, Alexander (eds.), Oxford guide to the Transeurasian Languages. 40-58. Oxford: Oxford University Press.

De Boer, Elisabeth M. In press. The Ramsey hypothesis. In Frellesvig, Bjarke \& Kinsui, Satoshi \& Whitman, John B. (eds.), Handbook of the history of the Japanese language. Berlin: Mouton de Gruyter.

De Boer, Elisabeth M. \& Yang, Melinda \& Kawagoe, Aileen \& Barnes, Gina. 2020. Japan considered from the hypothesis of farmer/language spread. Evolutionary Human Sciences 2. e13.

Fujiwara, Yoichi. 1988. Setonaikai hōgen jiten: Iyo Ōmi-shima Higai hōgen wo chūshin ni [Dictionary of the Seto Inland Sea dialects: concentrating on the Higai dialect of Iyo Ōmi Island]. Tokyo: Tōkyō-dō Shuppan.

Hayata, Teruhiro. 1973. Accent in Old Kyoto and some modern Japanese dialects. Gengo no Kagaku 4. 139-180.

Hirako, Tatsuya. 2015. Notojima sho-hōgen ni okeru akusento no henka [Changes in the accent of the dialects of Noto Island]. Nihongo no Kenkyū 11. 18-34.

Hirako, Tatsuya. 2017a. Izumo chiiki 7 hōgen no meishi akusento shiryō: 1-3 mora go [Materials on the accent of nouns in 7 dialects in the Izumo region: Words of 1-3 moras]. Jissen Kokubungaku 91. 11-53. 
Hirako, Tatsuya. 2017b. Akusento kara mita Izumo hōgen naibu no chiiki-sa: Bunpu to rekishi [Regional differences in the inner regions of the Izumo dialect from the viewpoint of accent: Distribution and history]. (Paper presented at the 2017 Spring Meeting of the Society for Japanese Linguistics, Osaka: Society for Japanese Linguistics, 13-14 May 2017).

Hirako, Tatsuya. 2017c. Gairin-shiki akusento no rekishi-teki ichizuke ni tsuite [On the historical position of the Gairin type accent systems]. Journal of Asian and African Studies 94. 259-276.

Hirayama, Teruo. 1957. Nihongo onchō no kenkyū [A study of Japanese tone]. Tokyo: Meiji Shoin.

Hirayama, Teruo. 196o. Zenkoku akusento jiten. [Accent dictionary of the entire country]. Tokyo: Tōkyōdō Shuppan.

Hiroto, Atsushi. 1950. San'in hōgen no kenkyū. [Study of the San'in dialects] Matsue: Shimane Kenritsu Kyōiku Kenshū-jo.

Hiroto, Atsushi. 1961. Chūgoku chihō no akusento [The accent of the Chūgoku region], Onsei no Kenkyū 9. 155-168.

Hiroto, Atsushi \& Ōhara, Takamichi. 1953. San'in chihō no akusento [The accent of the San'in region]. Matsue: Hōkō-sha.

Kindaichi, Haruhiko. 1951. Nihon shisei kogi [The old value of the four tones in Japan] In Terakawa, Kishio \& Kindaichi, Haruhiko \& Inagaki, Masayuki (eds.), Kokugo akusento ronsō. 629-708. Tokyo: Hōsei Daigaku Shuppan Kyoku.

Kindaichi, Haruhiko. 1954. Tōzai ryō-akusento no chigai ga dekiru made [Until there arose a difference between the eastern and the western accent types.] Bungaku 22(8), 63-84. (Reprinted in: Kindaichi 1983: 49-81.)

Kindaichi, Haruhiko (ed.). 1958. Meikai Nihongo akusento jiten [Meikai dictionary of Japanese accent]. Tokyo: Sanseidō. (Revised edition, 1981.)

Kindaichi, Haruhiko. 1983 Nihon no hōgen: Akusento hensen to sono jissō [The dialects of Japanese: Accentual change and its present state] Tokyo: Kyōiku Shuppan.

Kobayashi, Chieko. 1975. Japanese dialects: Phonology and reconstruction of the protoaccentual system. Cornell: Cornell University. (Doctoral dissertation).

Martin, Samuel E. 1987. The Japanese language through time, New Haven: Yale University Press.

Nakajō, Osamu. 1983. Shizuoka-ken no hōgen [The dialects of Shizuoka prefecture] In Iitoyo, Kiichi \& Hino Sukenari \& Satō Ryōichi (eds.), Kōza hōgen-gaku 6: Chūbu chihō no hōgen. 141-176. Tokyo: Kokusho Kankōkai.

Nihon Hōsō Kyōkai (NHK). 1985 Nihongo hatsuon akusento jiten Tokyo: Nihon Hōsō Shuppan Kyōkai.

Nitta, Tetsuo. 2005. Akusento-ron: Notojima no shiki no henka wo kangaeru [Accentology: Thinking about register change on Noto Island]. Kokubungaku Kaishaku to Kyōzai no Kenkyū 50(5).34-43. 
Okumura, Mitsuo. 1981. Koku-go akusento-shi no ichi-mondai: Izumo-hōgen no akusento wo chūshin ni [One problem in the accentual history of the national language: Concentrating on the accent of the Izumo dialect]. In Fujiwara Yoichi sensei koki gokenju shukuga ronshū kankō iinkai (ed.), Fujiwara Yoichi sensei koki kinen ronshū: Hōgen-gaku ronsō 2, Hōgen-kenkyū no shatei. 165-176. Tōkyō: Sanseidō.

Ramsey, S. Robert. 1979. The Old Kyōto dialect and the historical development of Japanese accent. Harvard Journal of Asiatic Studies 39. 157-175.

Ramsey, S. Robert. 198o. Nihongo akusento no rekishiteki henka [Historical change in the accent of Japanese]. Gengo 9(2). 64-76.

Tokugawa, Munemasa. 1962. Nihon sho-hōgen akusento no keifu shiron [Towards a family tree for accent in Japanese dialects]. Gakushüin Daigaku Kokugo Kokubun Gakkai-shi 6. 1-19.

Uwano, Zendō. 1981a. Matsue-shi hōgen no akusento: Fuzoku-go wo chūshin ni [The accent of the dialect of Matsue City: Concentrating on auxiliaries] Kanazawa Daigaku Nihonkai-ikii Kenkyū-jo Hōkoku 13. 109-136.

Uwano, Zendō. 1981b. Article accompanying the dialect map. In Wurm, Stephen A. \& Shirō Hattori (eds.), Language atlas of the Pacific area, no page number. Canberra: Australian Academy of Sciences/Japan Academy.

Uwano, Zendō. 2016. Izumo hōgen akusento chōsa hōkoku [Report on the accent survey of the Izumo dialects]. In Kibe Nobuko (ed.), Shōmetsu kiki hōgen no chōsa: Hozon no tame no sōgō-teki kenkyū. Tokyo: Kokuritsu Kokugo Kenkyū-jo, 23-31.

Vance, Timothy. 1987 An introduction to Japanese phonology. New York: State University of New York Press.

Yoshida, Yuko. 1997. Lexical accent assignment in standard Japanese: The benefit of a single pitch analysis. In Frellesvig, Bjarke \& Starrs, Roy (eds.), Japan and Korea contemporary studies. 92-98. Aarhus: Aarhus University Press. 